\title{
Expert elicitation of seasonal abundance of North Atlantic right whales Eubalaena glacialis in the mid-Atlantic
}

\author{
Cornelia Oedekoven ${ }^{1, *}$, Erica Fleishman ${ }^{2}$, Philip Hamilton ${ }^{3}$, James S. Clark ${ }^{4}$, \\ Robert S. Schick ${ }^{1}$ \\ ${ }^{1}$ Centre for Research into Ecological and Environmental Modelling, The Observatory, Buchanan Gardens, \\ University of St. Andrews, Fife KY16 9LZ, UK \\ ${ }^{2}$ John Muir Institute of the Environment, University of California, Davis, CA 95616, USA \\ ${ }^{3}$ John H. Prescott Marine Laboratory, New England Aquarium, Boston, MA 02110, USA \\ ${ }^{4}$ Nicholas School of the Environment, Duke University, Durham, NC 27708, USA
}

\begin{abstract}
North Atlantic right whales Eubalaena glacialis are among the most endangered of the large whales. Although protected since 1935, their abundance has remained low. Right whales occupy the Atlantic Ocean from southern Greenland and the Gulf of St. Lawrence south to Florida. The highly industrialized mid-Atlantic region is part of the right whales' migratory corridor, and gaps in knowledge of their movements through this region have limited the ability to make informed decisions about management of the species. To help fill these gaps, we elicited estimates of the relative abundance of adult right whales in the mid-Atlantic during 4 months (each month representing each season) from 10 experts on right whale ecology and management. We elicited the minimum, maximum, and mode as the number of individuals in a hypothetical population of 100 right whales, and confidence estimates as percentages. For each month-sex combination, we merged the 10 experts' answers into 1 distribution. The estimated modes of relative abundances of both sexes were highest in January and April (females: 29 and 59; males: 22 and 23) and lowest in July and October (females: 5 and 9; males: 3 and 5). In some cases, our elicitation results were consistent with the results of studies based on sightings data. However, these studies generally did not adjust for sampling effort, which was low and likely variable. Our results supplement the results of these studies and will increase the accuracy of priors in complementary Bayesian models of right whale abundances and movements through the mid-Atlantic.
\end{abstract}

KEY WORDS: Merged distributions - Migratory corridor - Survival - Triangular distributions · Weighting estimates

\section{INTRODUCTION}

The current population of North Atlantic right whales Eubalaena glacialis (henceforth right whales) is estimated to be about 500 individuals (www.narwc. org/pdf/2013_Report_Card.pdf). The species is one of the most highly endangered large whales (e.g. Caswell

\footnotetext{
${ }^{*}$ Corresponding author: cso2@st-andrews.ac.uk
}

et al. 1999, Clapham et al. 1999, Kraus et al. 2001, 2005). Although right whales were protected by the League of Nations in 1935, and subsequently by the International Whaling Commission, Convention on Trade in Endangered Species, US Marine Mammal Protection Act, US Endangered Species Act, and Canadian Species at Risk Act, their abundance has remained low.

() The authors 2015. Open Access under Creative Commons by Attribution Licence. Use, distribution and reproduction are unrestricted. Authors and original publication must be credited. 
Right whales occupy the Atlantic Ocean from southern Greenland and the Gulf of St. Lawrence south to Florida. In general, calving occurs during winter near the coast of the southeastern United States. In early spring, they can be found off Massachusetts within Cape Cod Bay and Massachusetts Bay; in late spring, they occur to the east of Cape Cod in the Great South Channel. During summer and autumn, right whales typically occupy the Bay of Fundy and the Roseway Basin off Nova Scotia. However, their movements differ substantially among individuals and years (Baumgartner \& Mate 2005), and estimates of the occupancy of a given region, the timing of migration between regions, and the proportion of individuals that migrate between regions are often uncertain. Collisions with ships and entanglement in fishing gear are the principal sources of mortality and sublethal injury of right whales (Kraus et al. 2005, Vanderlaan 2010, van der Hoop et al. 2015), and lack of knowledge about the species' movements has limited the ability to make informed decisions about management of the species. In particular, little is known about the whales' occurrence in the midAtlantic region, which we define as all waters north of Georgia $\left(32^{\circ} \mathrm{N}\right)$, south of Cape $\operatorname{Cod}\left(42^{\circ} \mathrm{N}\right)$, and west of the Great South Channel $\left(70^{\circ} \mathrm{W}\right)$ in accordance with the regional delineations in the North Atlantic Right Whale Catalog (http://rwcatalog.neaq. org).

The mid-Atlantic region connects the whales' feeding and nursery habitat in the Bay of Fundy and the Scotian Shelf south through New England with their wintering and calving habitat off the southeastern United States (Knowlton et al. 2002, Firestone et al. 2008). Pregnant females migrate southward through this area in autumn, and the same females migrate northward in spring with their young calves. In addition, other right whales migrate through the region to feed and socialize there (Whitt et al. 2013). The midAtlantic is highly industrialized, and exploration for offshore oil and gas along with construction and operation of offshore wind turbines is anticipated to expand (see, for example, Kraus \& Rolland 2007, NOAA 2008, BOEM 2015). Despite the importance of this area to the status of right whales, movements in the mid-Atlantic are difficult to study because the region is relatively large and the density of right whales is low.

Recent Bayes models of the movement and life history of right whales (Schick et al. 2013) have provided insight into the movements and health of individuals. These authors fitted hierarchical Bayes models (Clark \& Bjønstad 2004, Clark 2005, 2007,
Clark et al. 2005) to $32 \mathrm{yr}$ of sightings data. The research made use of informed prior distributions of movement transitions (priors) through 9 recognized regions occupied by right whales. These priors were based on one expert's opinion. In general, priors reflect belief about the magnitude of uncertainty in a parameter value. For example, if a prior is wellinformed, the value is assumed to have low uncertainty, whereas a flat (or uninformed) prior reflects high uncertainty in the value of a parameter. However, because few data on the movements or health of right whales from the mid-Atlantic exist, the priors for movement transitions through this region remained mostly uninformed. As a result, the number of right whales that occur in the mid-Atlantic and the probabilities of their movement through the region were likely underestimated in Schick et al. (2013). Prior-sensitivity analyses suggested that estimates of movement-especially into and out of the midAtlantic - depended strongly on the priors (see the 'Introduction' and Figs. S2 \& S3 in the Supplement at www.int-res.com/articles/suppl/n029p051_supp.pdf), with uninformed priors resulting in estimates that suggest few whales moved into and out of the midAtlantic.

One way to minimize the error inherent in developing model priors based on few data is to use expert elicitation (e.g. Martin et al. 2012, O'Hagan et al. 2006). However, extensive studies in psychology have demonstrated that experts have predictable, manageable cognitive biases (e.g. Tversky \& Kahneman 1974, Ericsson 1996) and that the judgment of the most knowledgeable individual in a group is consistently less accurate than the mean judgment of a diverse group. Accordingly, it is more reliable to use a structured method to seek information from multiple experts than to use information from a single individual.

Expert elicitation encompasses a rigorous set of methods for synthesizing knowledge to inform decision-making, and has proven reliable and practical when field data are limited (e.g. Donlan et al. 2010). It is useful for identifying plausible alternative hypotheses, estimating model parameters, and prioritizing collection of data that may have considerable bearing on policy or management decisions (Martin et al. 2012). The information may be elicited as point estimates or as distributions of parameters (Runge et al. 2011).

Here, we present estimates of the relative abundances of right whales in the mid-Atlantic throughout the year that we obtained through expert elicitation. For comparison, we present the corresponding 
estimates from the models of Schick et al. (2013) that were not previously published. The estimates obtained from our elicitation can be used to improve the accuracy of priors in future Bayes models of the abundances and movements of right whales through the mid-Atlantic region.

\section{MATERIALS AND METHODS}

Although the University of California, Davis' Institutional Review Board determined that human-subjects review was not required, we obtained informed consent from the 5 women and 5 men who participated in the elicitation (henceforth, experts). Experts were invited on the basis of their knowledge of the ecology and management of right whales as well as the diversity of their organizational affiliations, ages, and career stages. Collectively, the experts had a large amount of knowledge regarding historical whaling data, acoustic detections of right whales in the mid-Atlantic, photographic identification of right whales and data from surveys of the species, plankton density and feeding behavior of right whales, and right whale management. The age spread among the experts was approximately 25 to $30 \mathrm{yr}$.

Schick et al. (2013) used 9 regions within the distribution of right whales as delineated in the Right Whale Catalog, and estimated movement transitions of individual adults and juveniles among these regions during each month of the year. This resulted in $972(9 \times 9 \times 12)$ estimated transition probabilities for each sex and age class. Because it was not feasible to formally elicit information about such a large number of transitions from our group of experts, we focused on the mid-Atlantic region. We elicited information on the mean proportion of adult female and male right whales that were either present in, or moved into, the mid-Atlantic during each of 4 different months from 1995 through 2013. The 4 months (January, April, July, and October) were representative of winter, spring, summer, and autumn, respectively.

We developed a questionnaire on the distribution and movements of right whales (see the Supplement); questions were brief and distinct (Hoffrage \& Gigerenzer 1998). Here, we address 8 questions regarding the distribution of right whales. We used the responses to 6 questions about movements to develop priors for a model that will be reported separately.

Each of the questions consisted of 4 parts (SpeirsBridge et al. 2010): a low estimate (minimum value), a high estimate (maximum value), an estimate of the mode, and the participant's estimate of confidence in his or her answers to that question. We elicited minimum and maximum values as plausible quantities rather than theoretically possible quantities. Although we were interested in the proportion of the population occurring in the mid-Atlantic, we elicited the minimum, maximum, and mode as integers (the number of individuals in a hypothetical population of 100 right whales) rather than as proportions or percentages because people are generally able to conceptualize numbers better than percentages (Kynn 2008, Kuhnert et al. 2010). The confidence question was phrased as a percentage. The format of each question was the same with the exception of the variables (i.e. the whales' sex or the month) (Kynn 2008). In contrast to the methods of McBride et al. (2012), we did not provide the experts with background on the topics of the elicitation.

Before collecting answers to the questions, we distributed a draft of the questionnaire to the experts. We convened a conference call to review the intent of the elicitation and ensure consensus on terms in the questions and the quantities we aimed to elicit. We did not discuss answers to the questions, only the questions themselves. Following the call, we revised the questionnaire to improve its clarity. We then distributed the revised questionnaire (see the Supplement) and a description of the revisions to the experts via email. Participants were instructed to answer the questions on the basis of their knowledge of right whale biology without consulting anyone else. Answers were returned by email. We compiled the answers of each participant (range between minimum and maximum values, mode, and confidence estimate) and calculated the mean of the individual responses. The identity of the expert corresponding to each answer was kept confidential.

We convened the group of experts for an in-person meeting during which they discussed the set of answers to each question in turn. In some cases, experts voluntarily identified their responses. Following the discussion, each expert had the opportunity to revise his or her answers (analogous to a Delphi process; Delbecq et al. 1975). All experts who participated in this discussion changed their answers. We facilitated the discussion as needed, and it did not appear to us that the more experienced individuals dominated the discussion or influenced the answers of the less experienced individuals.

For each question, we merged the 10 experts' answers into a single distribution (Iman \& Conover 1982, Helbraun 2014, Donovan et al. in press). First, 
we formed 10 triangular distributions, one for each expert, on the basis of the minimum, maximum, and mode. Second, we drew 10000 random samples from each triangular distribution and weighted each random sample on the basis of the confidence estimate given by the experts. Third, we used these weights to draw another 10000 random samples from the first 100000 samples. This second set of samples formed the merged distribution of the experts' estimates. We assumed that the expected value of the merged distribution was the mean of the expected values of the 10 triangular distributions, each weighted by the confidence estimate. We also assumed that if ranges

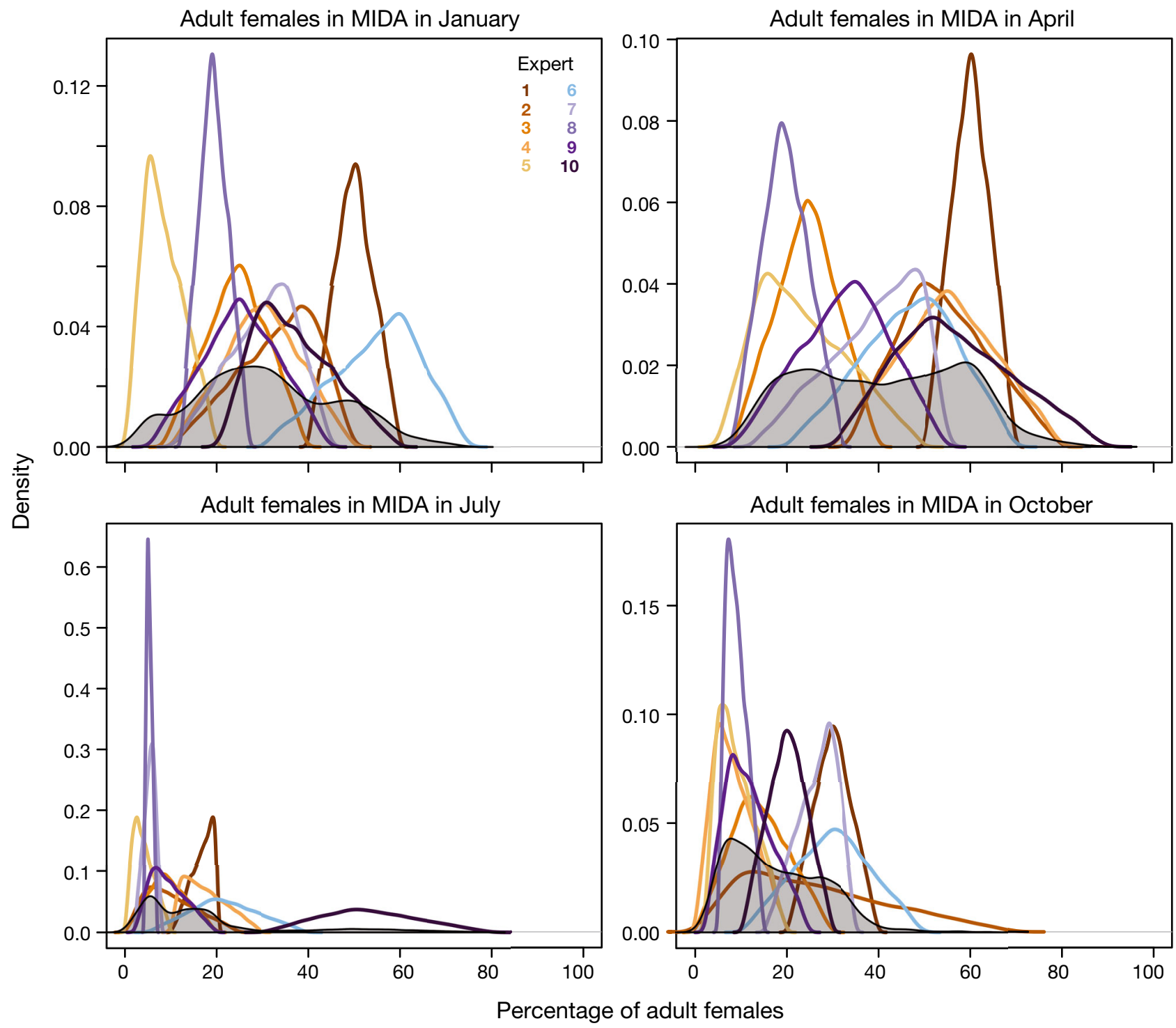

Fig. 1. Distributions (shown as probability density functions) of the percentage of adult female North Atlantic right whales Eubalaena glacialis estimated to occur in the mid-Atlantic region (MIDA) for any period of time during each of 4 months. Colored lines: estimates elicited from each of 10 experts; shaded polygon: merged distribution in which each of the 10 estimates was weighted on the basis of the expert's confidence in his or her estimate of values with relatively high probabilities overlapped, then these ranges of values would have relatively high probabilities in the merged distribution.

\section{RESULTS}

The shape of the merged distributions, which is described by the probability density function (PDF), did not approximate any of the standard distributions, such as the normal or gamma (Figs. 1 \& 2). The PDF can be used to calculate the probability of observing values that lie between 2 values. For example, the 

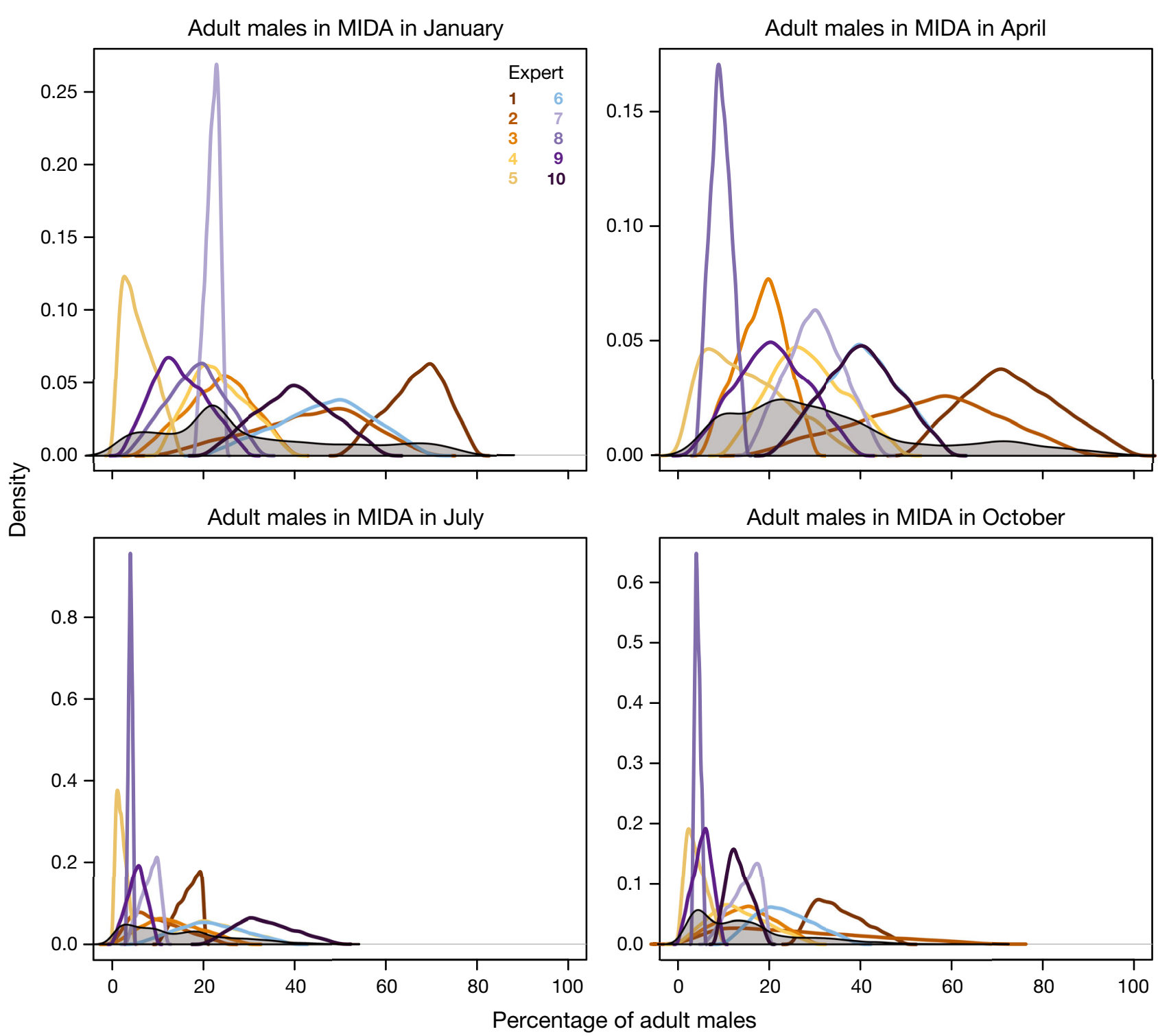

Fig. 2. Distributions (shown as probability density functions) of the percentage of adult male North Atlantic right whales Eubalaena glacialis estimated to occur in the mid-Atlantic region (MIDA) for any period of time during each of 4 months. Colored lines: estimates elicited from each of 10 experts; shaded polygon: merged distribution in which each of the 10 estimates was weighted on the basis of the expert's confidence in his or her estimate

probability of observing values between $x_{1}$ and $x_{2}$ is equal to the area under the PDF between $x_{1}$ and $x_{2}$.

For each month, the mean and mode of the merged distributions were higher for females than for males (Table 1). The highest mode (59 of the hypothetical population of 100) was for females in April. The estimated relative abundances of both sexes were highest in January and April (with modes over 20 and means over 30) and lowest in July. In July and October, the modes ranged from 3 through 8 , although the means were considerably larger than the modes (mean for females: 12 to 18 ; mean for males: 13 to 15 ).
The variability in the experts' answers was reflected in the large standard deviations (from 10.25 through 21.53; Table 1) and the wide range between minima and maxima for a given month, which varied from 49 to $99 \%$ of the population (Figs. $1 \& 2$ ). The estimated percentage of males in the mid-Atlantic in April ranged from $<1$ to $>99 \%$. Thus, according to our elicitation, it was possible that either none or all of the adult male right whales could be present in the midAtlantic in April. The minimum of 7 of the 8 merged distributions corresponding to the 8 questions was $<1$, and the minimum of the eighth distribution was $<10$. 
Table 1. Mean, mode, and standard deviation (SD) of the percentage of adult right whales (females and males) that occurred in (merged distributions) or moved into (hierarchical Bayes) the mid-Atlantic region at any point during the given month. Merged distributions were based on our elicitation of 10 experts' estimates, and values represent annual means for each of the months from 1995 through 2013. Hierarchical Bayes values reflect modeled means for each month from 1995 through 2011 (Schick et al. 2013)

\begin{tabular}{|lccccccc|}
\hline \multirow{2}{*}{ Estimate } & \multicolumn{3}{c}{ Merged distributions } & \multicolumn{3}{c|}{ Hierarchical Bayes } \\
& Mean & Mode & SD & Mean & Mode & SD \\
& & & & & & & \\
Adult females & & & & & & \\
January & 31.24 & 27.94 & 15.08 & 1.11 & 1.00 & 0.29 \\
April & 40.99 & 58.95 & 17.30 & 1.51 & 1.32 & 0.60 \\
July & 17.63 & 5.40 & 16.59 & 0.73 & 0.38 & 1.37 \\
October & 17.86 & 7.88 & 10.25 & 4.22 & 2.37 & 4.86 \\
Adult males & & & & & & \\
January & 30.65 & 22.02 & 20.18 & 0.60 & 0.56 & 0.15 \\
April & 33.74 & 22.55 & 21.53 & 0.87 & 0.78 & 0.21 \\
July & 14.39 & 3.18 & 10.71 & 0.26 & 0.20 & 0.14 \\
October & 14.83 & 4.50 & 11.27 & 1.91 & 1.66 & 0.79 \\
\hline
\end{tabular}

\section{DISCUSSION}

We elicited answers to questions regarding the distribution of North Atlantic right whales in the midAtlantic region from 10 experts on the species. Similar to McBride et al. (2012), we used a 4-part elicitation procedure (Speirs-Bridge et al. 2010) and allowed panel members to revise their answers after feedback and group discussion. McBride et al. (2012) used the percentage confidence provided by the experts with respect to each elicited value as confidence intervals, and used linear extrapolation to standardize the confidence intervals to $100 \%$ credible intervals around the best estimate. From these standardized intervals, McBride et al. (2012) used the Delphi method to obtain the mean of the group's best estimate of each value and the means of the normalized upper and lower bounds of the confidence intervals. In contrast, we used the percentage confidence to weight each expert's estimate when merging distributions for the parameters.

For each of the quantities we elicited, the estimates of the 10 experts varied considerably. Experts could include uncertainty in their estimates for each question in 2 ways: by adjusting the range (minimum to maximum) of possible numbers, and by specifying their confidence in their estimates. There was no evidence that experts consistently had higher confidence in estimates for which ranges were relatively narrow, or vice versa. Nevertheless, by merging the estimates from the 10 experts as described above, we mitigated potential overconfidence in the few instances in which one expert provided a narrow range and a high confidence (e.g. for adult females or males in July).

Despite the variability in the elicited estimates, we found that the proportion of female and male right whales estimated to occur in the mid-Atlantic during each of the 4 months was non-zero, and was higher in January and April than in July or October. Previously estimated percentages of adult females and males in the mid-Atlantic (Schick et al. 2013) were considerably smaller and less variable (Table 1). In Schick et al.'s (2013) study, all estimated means, modes, and standard deviations were $<5$. These relatively low estimates may reflect the historically low and variable sampling effort in the mid-Atlantic region; $15 \%$ of all sampling effort (measured as linear $\mathrm{km}$ surveyed) that contributed to the study was conducted in the mid-Atlantic region. The midAtlantic is about 1.65 times the sum of the sizes of all well-studied regions in which right whales feed, including Cape Cod Bay, Roseway Basin, the Great South Channel and the Bay of Fundy. More than $50 \%$ of the sampling in the mid-Atlantic was conducted from December through March. In addition, the number of right whales sighted in the midAtlantic region was low, and the priors (which were mostly uninformed for movements into this region) reflected the judgment of 1 rather than 10 experts (Schick et al. 2013). Moreover, estimated percentages of both females and males present in the midAtlantic region were highest in October (Schick et al. 2013), likely because the prior probabilities of movement into the mid-Atlantic region in October were slightly greater than those for January, April, or July. The discrepancies between the results of this elicitation and those of Schick et al.'s (2013) models suggest that right whale occurrence in the mid-Atlantic region may be higher than previously expected. On the basis of our results, we believe that additional survey effort and resulting sightings and/or acoustic data (e.g. Whitt et al. 2013) in the mid-Atlantic region are necessary in order to obtain accurate and precise estimates of the seasonal abundances and distribution in the region.

Sightings of right whales in the mid-Atlantic region were reported previously, although the definition of this region varied among reports. These sightings and our elicitation consistently suggest that right whales are present in the mid-Atlantic region throughout the year, with the abundance or proportion in the mid-Atlantic region peaking in the winter or early spring. For example, Knowlton et al. (2002) 
reported the number of sightings from each of the major harbors within the mid-Atlantic. The number of sightings was generally $<3$ for any given harbor in June, July, and August, although right whales were sighted in at least 1 harbor during each of those months. The number of sightings in each month was 5 or greater for at least 1 harbor from September through May; the highest numbers of sightings were 32, 41, 46, and 26 from December through March, respectively, in Savannah, Georgia.

Firestone et al. (2008) used regression analysis to model northerly movements of right whales through the mid-Atlantic. They estimated that right whales departed the southern calving grounds within a $30 \mathrm{~d}$ period that began in early to mid-March, and traveled for 21 to $24 \mathrm{~d}$ to reach the tip of Long Island, New York. The merged distributions from our elicitation, which indicated that the proportion of whales in the mid-Atlantic peaked in April, were consistent with these results.

Winn et al. (1986) reported 4, 30, 5 and 0 sightings (both sexes) in their combined regions of midAtlantic, Cape Hatteras and Long Island (which fall within our boundaries of the mid-Atlantic region) during January, April, July and October, respectively. The seasonal modes identified in both our elicitation and Winn et al. (1986) indicated that abundances in the mid-Atlantic were highest in April and lowest in July. However, our work suggested that abundances in the mid-Atlantic during January and October were higher than those suggested by the sightings data.

Although the results of our elicitation were somewhat consistent with the results of studies based on sightings data, sightings-based estimates of abundance in the mid-Atlantic generally were not adjusted for effort. Additionally, the estimates of experts may reflect not only published empirical sightings data but knowledge about the life history of the animals, personal experience at sea, unpublished sightings data, acoustic data, and other sources of information. Hence, we propose that the results from our elicitation supplement empirical studies, at least until more comprehensive and standardized empirical data are available.

Acknowledgements. This work was supported in part by US Office of Naval Research (ONR) grants to E.F.: N00014-09-10896 at University of California, Santa Barbara and N0001412-1-0274 at University of California, Davis. This work was also supported by ONR grant N000141210286 to the University of St. Andrews. In addition, we gratefully acknowledge funding for this work from The Marine Alliance for Science and Technology for Scotland (MASTS). MASTS is funded by the Scottish Funding Council (grant reference HR09011) and contributing institutions. Thanks to the 10 experts who took the time to participate in this elicitation. We thank the North Atlantic Right Whale Consortium for access to the databases, and are grateful to the many scientists who have contributed to this database.

\section{LITERATURE CITED}

Baumgartner MF, Mate BR (2005) Summer and fall habitat of North Atlantic right whales (Eubalaena glacialis) inferred from satellite telemetry. Can J Fish Aquat Sci 62: $527-543$

BOEM (Bureau of Ocean Energy Management) (2015) Notice of Availability (NOA) of and request for comments on the draft proposed outer continental shelf (OCS) oil and gas leasing program for 2017-2022 (DPP). Fed Regist 80:4931-4945

Caswell H, Fujiwara M, Brault S (1999) Declining survival probability threatens the North Atlantic right whale. Proc Natl Acad Sci USA 96:3308-3313

> Clapham PJ, Young SB, Brownell RL Jr (1999) Baleen whales: conservation issues and the status of the most endangered populations. Mammal Rev 29:35-60

Clark JS (2005) Why environmental scientists are becoming Bayesians. Ecol Lett 8:2-14

Clark JS (2007) Models for ecological data: an introduction. Princeton University Press, Princeton, NJ

Clark JS, Bjønstad ON (2004) Population time series: process variability, observation errors, missing values, lags, and hidden states. Ecology 85:3140-3150

> Clark JS, Ferraz G, Oguge N, Hays H, DiConstanzo J (2005) Hierarchical Bayes for structured, variable populations: from recapture data to life-history prediction. Ecology 86:2232-2244

Delbecq A, Van de Ven A, Gustafson D (1975) Group techniques for program planning: a guide to nominal group and Delphi processes. Scott, Foresman \& Company, Glenview, IL

- Donlan CJ, Wingfield DK, Crowder LB, Wilcox C (2010) Using expert opinion surveys to rank threats to endangered species: a case study with sea turtles. Conserv Biol 24:1586-1595

Donovan C, Harwood J, King S, Booth C, Caneco B, Walker $\mathrm{C}$ (in press) Expert elicitation methods in quantifying the consequences of acoustic disturbance from offshore renewable energy developments. In: Popper AN, Hawkins $\mathrm{AD}$ (eds) Advances in experimental medicine and biology, Vol 875: the effects of noise on aquatic life II. Springer, New York, NY

Ericsson KA (1996) The acquisition of expert performance: an introduction to some of the issues. In: Ericsson KA (ed) The road to excellence: the acquisition of expert performance in the arts and sciences, sports, and games. Eribaum, Mahwah, NJ, p 1-50

> Firestone J, Lyons SB, Wang C, Corbett JJ (2008) Statistical modeling of North Atlantic right whale migration along the mid-Atlantic region of the eastern seaboard of the United States. Biol Conserv 141:221-232

Helbraun M (2014) Forecasting by combining expert opinion. http://blog.revolutionanalytics.com/2014/01/forecastingby-combining-expert-opinion.html (accessed 15 Nov 2014)

Hoffrage U, Gigerenzer G (1998) Using natural frequencies to improve diagnostic inferences. Acad Med 73:538-540 
Iman R, Conover W (1982) A distribution-free approach to inducing rank correlation among input variables. Comm Stat Simul Comput 11:311-334

Knowlton AR, Ring JB, Russell B (2002) Right whale sightings and survey effort in the mid-Atlantic region: migratory corridor, time frame, and proximity to port entrances. Report submitted to the NMFS Ship Strike Working Group. www.greateratlantic.fisheries.noaa.gov/ shipstrike/ssr/midatanticreportrFINAL.pdf

Kraus SD, Rolland R (2007) The urban whale: North Atlantic right whales at the cross-roads. Harvard University Press, Cambridge, MA

Kraus SD, Hamilton PK, Kenney RD, Knowlton AR, Slay CK (2001) Reproductive parameters of the North Atlantic right whale. J Cetacean Res Manag 2 (Spec Issue): 231-326

Kraus SD, Brown MW, Caswell H, Clark CW and others (2005) North Atlantic right whales in crisis. Science 309: 561-562

Kuhnert PM, Martin TG, Griffiths SP (2010) A guide to eliciting and using expert knowledge in Bayesian ecological models. Ecol Lett 13:900-914

Kynn M (2008) The heuristics and biases bias in expert elicitation. J R Stat Soc Ser A Stat Soc 171:239-264

Martin TG, Burgmann MA, Fidler F, Kuhnert PM, Low-Choy S, McBride M, Mengersen K (2012) Eliciting expert knowledge in conservation science. Conserv Biol 26: 29-38

McBride MF, Garnett ST, Szabo JK, Burbidge AH and others (2012) Structured elicitation of expert judgments for threatened species assessment: a case study on a continental scale using email. Methods Ecol Evol 3:906-920

NOAA (National Oceanic and Atmospheric Administration) (2008) Endangered fish and wildlife; final rule to imple-

Editorial responsibility: Helene Marsh, Townsville, Queensland, Australia ment speed restrictions to reduce the threat of ship collisions with North Atlantic right whales. Fed Regist 73: 60173-60191

O'Hagan A, Buck CE, Daneshkhah A, Eiser JR and others (2006) Uncertain judgements: eliciting experts' probabilities. John Wiley \& Sons, Chichester

Runge MC, Converse SJ, Lyons JE (2011) Which uncertainty? Using expert elicitation and expected value of information to design an adaptive program. Biol Conserv 144:1214-1223

Schick RS, Kraus SD, Rolland RM, Knowlton AR and others (2013) Using hierarchical Bayes to understand movement, health, and survival in the endangered North Atlantic right whale. PLoS ONE 8:e64166

Speirs-Bridge A, Fidler F, McBride M, Flander L, Cumming G, Burgman M (2010) Reducing overconfidence in the interval judgments of experts. Risk Anal 30:512-523

Tversky A, Kahneman D (1974) Judgment under uncertainty: heuristics and biases. Science 185:1124-1131

> van der Hoop JM, Vanderlaan ASM, Cole TVN, Henry AG and others (2015) Vessel strikes to large whales before and after the 2008 ship strike rule. Conserv Lett 8:24-32

Vanderlaan ASM (2010) Estimating risk to the North Atlantic right whale (Eubalaena glacialis) from oceangoing vessels and fishing gear. PhD dissertation, Dalhousie University, Halifax

- Whitt AD, Dudzinski K, Laliberté JR (2013) North Atlantic right whale distribution and seasonal occurrence in nearshore waters off New Jersey, USA, and implications for management. Endang Species Res 20:59-69

Winn HE, Price CA, Sorensen PW (1986) The distributional biology of the right whale Eubalaena glacialis in the western North Atlantic. Rep Int Whaling Comm (Spec Issue) 10:129-138

Submitted: March 24, 2015; Accepted: August 30, 2015 Proofs received from author(s): October 16, 2015 